\title{
Optimization of PMAxx pretreatment to distinguish between human norovirus with intact and altered capsids in shellfish and sewage samples
}

\author{
Randazzo Walter ${ }^{1,2}$, Khezri Mohammad ${ }^{3}$, Ollivier Joanna ${ }^{4}$, Le Guyader Soizick ${ }^{4}$, \\ Rodríguez-Díaz Jesús ${ }^{1,5}$, Aznar Rosa ${ }^{1,2}$, Sánchez Gloria ${ }^{2,}$
}

${ }^{1}$ Department of Microbiology and Ecology, University of Valencia, Av. Dr. Moliner, 50, 46100 Burjassot, Valencia, Spain

${ }^{2}$ Department of Preservation and Food Safety Technologies, IATA-CSIC, Av. Agustín Escardino 7, 46980 Paterna, Valencia, Spain

${ }^{3}$ Department of Seafood Processing, Faculty of Marine Science, Tarbiat Modares University, Noor, Iran

${ }^{4}$ Laboratoire de Microbiologie, LSEM-SG2M, IFREMER, BP 21105, 44311 Nantes Cedex 03, France

${ }^{5}$ Institute for Clinical Research of the Hospital Clínico Universitario (INCLIVA), Valencia, Spain

*Corresponding author : Gloria Sanchez, email address : gloriasanchez@iata.csic.es

\begin{abstract}
:
Shellfish contamination by human noroviruses (HuNoVs) is a serious health and economic problem. Recently an ISO procedure based on RT-qPCR for the quantitative detection of HuNoVs in shellfish has been issued, but these procedures cannot discriminate between inactivated and potentially infectious viruses. The aim of the present study was to optimize a pretreatment using PMAxx to better discriminate between intact and heat-treated HuNoVs in shellfish and sewage. To this end, the optimal conditions (30 min incubation with $100 \mu \mathrm{M}$ of PMAxx and $0.5 \%$ of Triton, and double photoactivation) were applied to mussels, oysters and cockles artificially inoculated with thermally-inactivated ( $99^{\circ} \mathrm{C}$ for $5 \mathrm{~min}$ ) HuNoV GI and GII. This pretreatment reduced the signal of thermally-inactivated HuNoV GI in cockles and HuNoV Gll in mussels by $>3$ log. Additionally, this pretreatment reduced the signal of thermallyinactivated HuNoV GI and Gll between 1 and $1.5 \mathrm{log}$ in oysters. Thermal inactivation of HuNoV GI and GII in PBS, sewage and bioaccumulated oysters was also evaluated by the PMAxx-Triton pretreatment. Results showed significant differences between reductions observed in the control and PMAxx-treated samples in PBS following treatment at 72 and $95^{\circ} \mathrm{C}$ for $15 \mathrm{~min}$. In sewage, the RT-qPCR signal of HuNoV GI was completely removed by the PMAxx pretreatment after heating at 72 and $95^{\circ} \mathrm{C}$, while the RT-qPCR signal for HuNoV Gll was completely eliminated only at $95^{\circ} \mathrm{C}$.
\end{abstract}

Finally, the PMAxx-Triton pretreatment was applied to naturally contaminated sewage and oysters, resulting in most of the HuNoV genomes quantified in sewage and oyster samples (12 out of 17) corresponding to undamaged capsids. Although this procedure may still overestimate infectivity, the PMAxx-Triton pretreatment represents a step forward to better interpret the quantification of intact HuNoVs in complex matrices, such as sewage and shellfish, and it could certainly be included in the procedures based on RT-qPCR. 


\section{Highlights}

- An optimized PMAxx-Triton treatment has been developed for shellfish. Differences were observed in PMAxx-Triton treated norovirus heated at 72 and $95^{\circ} \mathrm{C}$. In sewage and oysters, most of HuNoV genomes corresponded to undamaged capsids.

Keywords : Intercalating dyes, Viability PCR, Norovirus, Shellfish, Sewage, RT-qPCR 


\section{Introduction}

Diarrheal diseases caused by human noroviruses $(\mathrm{HuNoV})$ are one of the most common illnesses resulting from consumption of contaminated food (WHO, 2015). In the USA, foodborne transmission is estimated to account for $23 \%$ of HuNoV outbreaks (Hall et al., 2014). In the European Union, crustaceans, shellfish and mollusks were the most commonly implicated food vehicles (27.8\% of HuNoV outbreaks in 2015), followed by other foods (19.4\%) (EFSA and ECDC, 2016). Also in Europe, the consumption of oysters contaminated with HuNoVs cause 11,800 illnesses per year in the UK (Hassard et al. (2017). In the United States, the annual economic burden due to $\mathrm{HuNoV}$ infections and attributed to shellfish contamination is estimated to be US\$184 million (Batz et al., 2011).

Most shellfish-borne outbreaks caused by HuNoVs have been associated with the consumption of raw or under-cooked shellfish, especially oysters (Iritani et al., 2014; Lunestad et al., 2016), usually harvested from waters affected by the discharge of treated and untreated sewage (Campos and Lees, 2014). In addition, the scientific community agrees on the inadequacy of commercial shellfish depuration processes for HuNoVs (Le Mennec et al., 2017; McLeod et al., 2017) that could be explained by the presence of oyster ligands which specifically bind HuNoVs (Le Guyader et al., 2012).

The development of rapid, specific, sensitive, and standardized procedures for HuNoV detection in shellfish is of great interest. Recently a standardized RT-qPCR based procedure has been issued for HuNoV genogroup I (GI) and GII in several food matrices, including shellfish, berries and vegetables (Comite Europeen de Normalisation, 2017). RT-qPCR methods detect the viral RNA of both infectious and inactivated HuNoVs, potentially overestimating the amount of infectious viruses (Butot et al., 2009; Hewitt and Greening, 2006; Sanchez et al., 2011). To overcome this limitation, different strategies have been evaluated to predict infectivity using PCR-based methods, such as: (i) pretreatment with nucleases and/or proteolytic enzymes prior to nucleic acid extraction, eliminating the signal of nucleic acids belonging to damaged or inactivated viruses (Lamhoujeb et al., 2008; Nowak et al., 2011), (ii) using the HuNoV ability to bind porcine gastric mucin (PGM) (Tan and Jiang, 2005; Tang et al., 2010) 
which allows for selective recovery of potentially infectious HuNoVs in foods (Dancho et al., 2012), and (iii) pretreatment with nucleic acid intercalating dyes, such as ethidium monoazide (EMA) or propidium monoazide (PMA) (reviewed by Elizaquivel et al., 2014; Escudero-Abarca et al., 2014; Parshionikar et al., 2010). This latter approach is based on the ability of intercalating dyes (e.g. PMA or EMA) to penetrate only damaged or altered capsids and intercalate covalently into a viral genome after exposure to strong visible light, thus interfering with PCR amplification. Interestingly, this approach proved to reduce RT-qPCR signals for damaged enteric viruses in naturally contaminated water samples (Blanco, Guix, Fuster, Fuentes, Bartolomé, et al., 2017; Falco et al., 2017; Fuster et al., 2016; Leifels et al., 2015; Prevost et al., 2016; Randazzo et al., 2016a). Moreover, Moreno et al. (2015) applied PMA pretreatments to detect infectious hepatitis A virus (HAV) in vegetable and shellfish samples. PMAxx combined with RT-qPCR has been reported to be a very efficient intercalating dye for assessing viral infectivity discriminating between $\mathrm{HAV}$ and $\mathrm{HuNoV}$ with intact and altered capsids in vegetables and irrigation waters (Falco et al., 2017; Randazzo et al., 2016a). In the present work, we optimize the PMAxx pretreatment to better discriminate between intact and heat-treated HuNoVs in shellfish and sewage. Additionally, naturally contaminated sewage and shellfish samples were analyzed to evaluate the performance of the PMAxx pretreatment.

\section{Materials and Methods}

\subsection{Viral strains}

Fecal samples containing HuNoV genogroup I genotype 4 (GI·P4) and genogroup II genotype 4 (GII.4 variant Den Haag 2006b) were kindly provided by Dr. Buesa, University of Valencia, Spain. Fecal samples containing HuNoV GI.1 and GII.3 were used for bioaccumulation experiments. Stool samples were suspended $(10 \%, \mathrm{wt} / \mathrm{vol})$ in phosphate-buffered saline (PBS) containing $2 \mathrm{M} \mathrm{NaNO}_{3}$ (Panreac), 1\% beef extract (Conda), and 0.1\% Triton X-100 (Fisher Scientific) ( $\mathrm{pH} 7.2)$, vortexed and centrifuged at $1000 \times \mathrm{g}$ for $5 \mathrm{~min}$. The supernatant was stored at $-80^{\circ} \mathrm{C}$ in aliquots. 
The cytopathogenic strain MC0 of mengovirus (courtesy of Prof. Albert Bosch, University of Barcelona) was propagated and assayed in HeLa cells. Semi-purified viruses were harvested by three freeze-thaw cycles of infected cells followed by centrifugation at $660 \times \mathrm{g}$ for $30 \mathrm{~min}$ to remove cell debris. Infectious viruses were enumerated by determining the $50 \%$ tissue culture infectious dose $\left(\mathrm{TCID}_{50}\right)$ with eight wells per dilution and $20 \mu \mathrm{l}$ of inoculum per well using the Spearman-Karber method (Pinto et al., 1994).

\subsection{Sewage and shellfish samples}

Sewage samples collected from the municipal wastewater treatment plant of Quart (Valencia) from September to December 2016. The plant treats the flow from seven municipalities accounting for 164,171 equivalent inhabitants at a projected flow of $60,000 \mathrm{~m}^{3} /$ day. Sewage samples were concentrated by ultracentrifugation as described by Rodriguez-Diaz et al. (2009). Briefly, $35 \mathrm{ml}$ of sewage was centrifuged at $140,000 \times g$ for $2 \mathrm{~h} 30 \mathrm{~min}$ at $4{ }^{\circ} \mathrm{C}$. Then the pellet was eluted by incubating on ice for 30 min with $5 \mathrm{ml}$ of $0.25 \mathrm{~N}$ glycine buffer (pH 9.5). The solution was neutralized by adding $5 \mathrm{ml}$ of $2 \times$ PBS. The suspended solids were removed by centrifugation $(12,000 \times g$ for $15 \mathrm{~min})$, and viruses were finally recovered by centrifugation at $229,600 \times g$ for $1 \mathrm{~h}$ at $4^{\circ} \mathrm{C}$ in an 70Ti rotor. Viral particles were resuspended in $500 \mu \mathrm{l}$ of $1 \times$ PBS. Mengovirus was added in the $35 \mathrm{ml}$ of sewage as a process control virus to monitor extraction efficiency following the ISO 15216:2017 guidelines (Comite Europeen de Normalisation, 2017).

Oysters samples were collected from January to March 2013 (4 samples) and on February 2014 (2 samples) and were processed as described in the ISO 15216-1:2017 (Comite Europeen de Normalisation, 2017). Mengovirus was added as an extraction efficiency control to each dissected tissue ( $2 \mathrm{~g}$ ) before homogenization according the ISO 15216:2017 guidelines (Comite Europeen de Normalisation, 2017)

\subsection{Performance of PMAxx pretreatment in artificially contaminated shellfish}

Mussels (Mytilus galloprovincialis), oysters (Crassostrea gigas) and cockles (Cerastoderma edule) were purchased at a local market and tested for HuNoV GI and GII contamination following the ISO 15216-1:2017 procedure (Comite Europeen de Normalisation, 2017). 
Shellfish concentrates were initially prepared as described in the ISO 15216-1:2017. Briefly, $2 \mathrm{~g}$ of digestive tissues were transferred to a tube containing $2 \mathrm{ml}$ of proteinase $\mathrm{K}$ solution (30 $\mathrm{U} / \mathrm{mg}$ ). This mixture was incubated at $37^{\circ} \mathrm{C}$ with shaking for $60 \mathrm{~min}$, followed by incubation at $60{ }^{\circ} \mathrm{C}$ for $15 \mathrm{~min}$. Then a centrifugation at $3,000 \mathrm{~g}$ for $5 \mathrm{~min}$ was performed. Due to the presence of inhibitors an additional centrifugation at $8000 \times g$ for 20 min was included at the end of the procedure. Moreover, RNase inhibitor (40 U, Roche Diagnostics) was added to 100 $\mu 1$ of shellfish supernatants. Shellfish supernatants were inoculated with two different concentrations (ca. 3 and $4 \log$ RT-PCRU per $100 \mu$ of shellfish supernatant) of thermallyinactivated $\left(99{ }^{\circ} \mathrm{C}\right.$ for $\left.5 \mathrm{~min}\right) \mathrm{HuNoV}$ GI and GII suspensions. Then, samples were aliquoted into $100 \mu \mathrm{l}$ and added to $100 \mu \mathrm{M}$ PMAxx and $0.5 \%$ Triton 100-X (Fisher-Scientific). Samples treated with PMAxx were incubated in the dark at room temperature for $30 \mathrm{~min}$ at $150 \mathrm{rpm}$ and immediately exposed to 2 cycles of 15 -min photoactivation using a photo-activation system (Led-Active Blue, GenIUL) with a dark incubation of 15 min between photoactivations. Finally, $100 \mu \mathrm{l}$ of the sample were mixed with $25 \mu \mathrm{l}$ of the Plant RNA Isolation Aid (Ambion) and 600 $\mu 1$ of lysis buffer from the NucleoSpin ${ }^{\circledR}$ RNA virus kit (Macherey-Nagel GmbH \& Co.) and subjected to pulse-vortexing for $1 \mathrm{~min}$. Afterwards, the homogenate was centrifuged for $5 \mathrm{~min}$ at $10,000 \times g$ to remove the debris. The supernatant was subsequently processed using the NucleoSpin ${ }^{\circledR}$ RNA virus kit according to the manufacturer's instructions. Positive control samples (shellfish supernatants inoculated with thermally-inactivated HuNoV GI and GII suspensions) without PMAxx treatment were used to calculate the viral reduction titer. Efficacy of the PMAxx pretreatment was estimated by comparing the number of genome copies of thermally-inactivated HuNoV without the PMAxx pretreatment in a specific shellfish matrix and on the PMAxx-pretreated samples.

\subsection{Virus quantification}

We performed a standardized one-step TaqMan RT-qPCR using the RNA UltraSense One-Step quantitative system (Invitrogen SA) with a half-scale modification of the manufacturer's protocol. The LightCycler 480 instrument (Roche Diagnostics) was used to determine the 
number of genome copies of HuNoV GI, GII and Mengovirus according the ISO 15216-1:2017 (Comite Europeen de Normalisation, 2017). Undiluted sample RNA and ten-fold diluted RNA (to check for RT-qPCR inhibition) were analyzed in duplicate. A standard curve for HuNoV GI, GII and mengovirus were generated by amplifying 10-fold dilutions of viral suspensions by RTqPCR in quintuplicates, and the numbers of PCRU were calculated. Amplification was performed for 1 cycle of $55{ }^{\circ} \mathrm{C}$ for $1 \mathrm{~h}, 1$ cycle of $95{ }^{\circ} \mathrm{C}$ for $5 \mathrm{~min}$, and 45 cycles of $95{ }^{\circ} \mathrm{C}$ for 15 $\mathrm{s}, 60^{\circ} \mathrm{C}$ for $1 \mathrm{~min}$ and $65^{\circ} \mathrm{C}$ for $1 \mathrm{~min}$.

\subsection{Bioaccumulation experiments}

Live oysters (Crassostrea gigas) were purchased at local producer and then transfer to the IFREMER facilities. There, oysters were immediately rinsed and transferred into large seawater aquariums equipped with constant aeration. After 24 hours of immersion at the designated temperature adjusted to the season $\left(8-13{ }^{\circ} \mathrm{C}\right)$, oysters were individually checked and only live oysters showing filtration activity were included in the experiments. Before all bioaccumulation experiments, oysters were tested for HuNoV GI and GII contamination following the ISO 15216-1:2017 procedure. For bioaccumulation, one aquarium was filled with $20 \mathrm{~L}$ of seawater and seeded with a mixture of HuNoV GI.1 and GII.3 suspensions. Forty five oysters were added to each aquarium, yielding a ratio of 5 liters of water per kilogram of oysters (including the shell weight) as previously described (Drouaz et al., 2015). At 24 hours post seeding the oysters were collected and immediately dissected and frozen.

\subsection{Thermal treatment of HuNoV GI and GII in PBS, sewage and bioaccumulated oysters}

HuNoV suspensions in PBS pH 7.2 (3-4 log PCRU), a concentrated HuNoV-positive sewage sample and supernatant from bioaccumulated oysters supernatant were incubated at 60, 72 and $95{ }^{\circ} \mathrm{C}$ for $15 \mathrm{~min}$ in a thermal block to achieve different degrees of viral inactivation. An aliquot of each sample was kept at room temperature during heat treatment and used as a control sample. Then, an aliquot of control and heat-treated samples were further subjected to PMAxx pretreatment. For HuNoV suspensions in PBS and sewage, samples were added to $50 \mu \mathrm{M}$ PMAxx and $0.5 \%$ Triton, and then incubated in the dark at room temperature for $10 \mathrm{~min}$ in a shaker at $150 \mathrm{rpm}$ and immediately exposed to continuous LED light (464 to $476 \mathrm{~nm}$ ) for 15 
min using a photo-activation system (Randazzo et al., 2016a). For bioaccumulated oyster samples, the pretreatment consisted of $100 \mu \mathrm{M}$ PMAxx and $0.5 \%$ Triton together with a double photoactivation as detailed above. Heat-treated samples without PMAxx treatment were used to calculate the viral reduction titer. After intercalating dye pretreatments, RNA was extracted using the NucleoSpin® RNA virus kit (according to the manufacturer's instructions) and with plant RNA Isolation Aid treatment in case of sewage and shellfish samples (as detailed above).

\subsection{Analysis of naturally contaminated sewage and oyster samples}

One-hundred $\mu \mathrm{l}$ aliquots of concentrated sewage samples were added with $50 \mu \mathrm{M}$ PMAxx and 0.5\% Triton (PMAxx-Triton). Photoactivation, plant RNA Isolation Aid treatment, RNA extraction and RT-qPCR were performed as described above. Three different controls were included: i) $100 \mu \mathrm{l}$ of concentrated samples were processed without performing the PMAxxTriton pretreatment; ii) $100 \mu \mathrm{l}$ of concentrated samples were heated at $99{ }^{\circ} \mathrm{C}$ for $5 \mathrm{~min}$ and analyzed by RT-qPCR; iii) $100 \mu \mathrm{l}$ of concentrated samples were heated at $99^{\circ} \mathrm{C}$ for $5 \mathrm{~min}$ and analyzed by PMAxx-Triton-RT-qPCR

For shellfish, $100 \mu \mathrm{l}$ of shellfish supernatant were added with $100 \mu \mathrm{M}$ PMAxx and $0.5 \%$ of Triton, incubated for $30 \mathrm{~min}$ and photoactivated twice with an additional dark incubation of 15 min between photoactivations. RNA extraction and RT-qPCR were performed as described above. Three different controls were included: i) $100 \mu$ of shellfish supernatant were processed without performing the PMAxx-Triton pretreatment; ii) $100 \mu$ of shellfish supernatant were heated at $99^{\circ} \mathrm{C}$ for 5 min and analyzed by RT-qPCR; iii) $100 \mu$ of of shellfish supernatant were heated at $99{ }^{\circ} \mathrm{C}$ for $5 \mathrm{~min}$ and analyzed by PMAxx-Triton-RT-qPCR. The efficiency of the procedure was calculated by comparing the detected and added mengovirus genomes.

\subsection{Statistical analyses}

Results from at least four replicates were statistically analyzed using ANOVA with STATISTICA software version 10 (StatSoft Inc., Tulsa, OK, USA) and Tukey's test on a completely randomized design. A P value $<0.05$ was deemed significant. 


\section{Results and Discussion}

\subsection{Efficiency of the PMAxx pretreatment on artificially inoculated shellfish}

Last year, the European Commission launched a monitoring program to estimate the European prevalence of $\mathrm{HuNoV}$ contamination in oysters collected from representative monitoring points at production areas and dispatch centers using the ISO 15216-1 (European Food Safety, 2016). However, the number of virus genome copies detected by RT-qPCR does not always correlate with the number of infectious virus particles (Butot et al., 2008; Hewitt and Greening, 2004), and it is important to consider that the infectious risk associated with the levels of HuNoVs in oysters, as determined by RT-qPCR, may be overestimated. Therefore, the use of strategies to remove the RNA from inactivated viruses will improve the risk associated with water and food samples (Blanco, Guix, Fuster, Fuentes, Bartolome, et al., 2017; Randazzo et al., 2016b) .

In a previous study, our group demonstrated that a pretreatment of $50 \mu \mathrm{M}$ PMAxx combined with $0.5 \%$ of Triton was the most efficient pretreatment to discriminate between intact and thermally-inactivated HuNoV GI and GII, in different types of vegetables (Randazzo et al., 2016a). When this procedure was initially applied in shellfish samples, performance of the pretreatment had very limited effect on HuNoV titers due to the complexity of the matrix (data not shown) and the pretreatment has been modified ( i.e., increased concentration of PMAxx, 30 min of incubation time and double photoactivation). To validate the improved efficiency of this pretreatment to detect potentially infectious HuNoVs in shellfish, two concentrations of thermally-inactivated HuNoV GI and GII suspensions were artificially inoculated in shellfish, specifically mussels, oysters and cockles. Table 1 shows that the PMAxx-Triton pretreatment completely prevented RT-qPCR detection of thermally-inactivated HuNoV GII in mussels at high and low inoculation levels, while for HuNoV GI this pretreatment only reduced the RTqPCR signal by approximately $1 \log$. In oysters, a similar pattern was observed for HuNoV GI and GII, being that the signal was completely removed for thermally-inactivated HuNoV GII at low inoculation levels. A completely different behavior was reported in common cockles, where the RT-qPCR signal was removed for thermally-inactivated HuNoV GI and not for HuNoV GII. An explanation for these differences could be the presence of different compounds, depending 
on shellfish species, season or place of harvesting, which may facilitate or interfere with the performance of the PMAxx pretreatment.

\subsection{Performance of the PMAxx-Triton pretreatment to monitor heat treatments}

In order to assess the ability of PMAxx to monitor HuNoV inactivation after heating, initially HuNoV suspensions in PBS were treated at 60,72 and $95{ }^{\circ} \mathrm{C}$ for 15 min and immediately evaluated by RT-qPCR and PMAxx-Triton-RT-qPCR. As previously reported (EscuderoAbarca et al., 2014; Li et al., 2017), HuNoV RNA levels in PBS remained constant regardless of temperature treatment when evaluated by RT-qPCR (Table 2 and 3). When amplification was preceded by a PMAxx-Triton pretreatment, the RT-qPCR signal from HuNoV GI in PBS was easier to remove than the signal of HuNoV GII. Recently, Ettayebi et al. (2016) reported that heating at $60^{\circ} \mathrm{C}$ for $15 \mathrm{~min}$ resulted in complete inactivation of HuNoV GII.4 and GII.3 following evaluation by culture in human intestinal enteroids. When a treatment at $60{ }^{\circ} \mathrm{C}$ for 15 min was evaluated by PMAxx-Triton RT-qPCR a relative high reduction of RNA levels (approximately $2.8 \mathrm{log}$ ) was observed for $\mathrm{HuNoV}$ GI (Table 2), while no reduction was detected for HuNoV GII. For HuNoV GI, there was no further reduction after the PMAxx pretreatment, regardless of holding temperature, while for $\mathrm{HuNoV}$ GII at 72 and $95{ }^{\circ} \mathrm{C}$, the RNA copy number decreased by approximately $1.5 \log$. These results are in line with recent findings where a PMA pretreatment $(250 \mu \mathrm{M})$ of heat-treated $\left(85^{\circ} \mathrm{C}\right.$ for $\left.1 \mathrm{~min}\right) \mathrm{HuNoV}$ GII.4 suspensions reduced the RT-qPCR signal by $1.6 \log$ (Jeong et al., 2017).

The results at $60^{\circ} \mathrm{C}$ for $\mathrm{HuNoV}$ GII indicated that infectivity might be lost (Ettayebi et al., 2016), but their capsids did not allow the penetration of PMAxx because no reduction of RNA levels was observed. These discrepancies may be due to the fact that heat treatment at $60{ }^{\circ} \mathrm{C}$ may lead to changes in capsid conformation and, in turn, a loss of infectivity without compromising capsid integrity. These results are consistent with discrepancies found for HAV when applying the same thermal treatments and comparing the PMAxx pretreatment and infectivity by cell-culture (Falco et al., 2017), since HAV infectivity was reduced by 3.00, 3.75 
and $>5.05 \operatorname{logs} \mathrm{TCID}_{50}$, after treatments at 60,72 and $95{ }^{\circ} \mathrm{C}$, while the decrease of HAV titers after the PMAxx pretreatment was 1.32, 3.03 and >3.18 logs, respectively.

In addition, a naturally contaminated sewage sample positive with HuNoV GI and GII and a bioaccumulated oyster supernatant were also treated at 60,72 and $95{ }^{\circ} \mathrm{C}$ for $15 \mathrm{~min}$. While the HuNoV RNA levels in the sewage remained unchanged when evaluated by RT-qPCR, regardless of temperature treatment applied, almost one log of reduction was observed in bioaccumulated oysters after heating at $95{ }^{\circ} \mathrm{C}$ (Table 3). A plausible explanation for the decrease of RNA levels after heating oyster supernatants would be the action of RNases, despite the presence of an RNase inhibitor in the samples.

Additionally, the RT-qPCR signal of HuNoV GI was completely removed by the PMAxx pretreatment after heating sewage samples at 72 and $95{ }^{\circ} \mathrm{C}$ (Table 2), while the PMAxx pretreatment for HuNoV GII completely eliminated the RT-qPCR signal only at $95{ }^{\circ} \mathrm{C}$ (Table 3). In bioaccumulated oysters, the PMAxx-Triton pretreatment was partially effective only in oysters treated at $95^{\circ} \mathrm{C}$, with one $\log$ reduction of the RT-qPCR signal. Differences observed in the performance of the PMAxx pretreatment between PBS, sewage and oysters are most likely due to matrix; however, strain variability, in terms of thermal resistance and capsid constrains, may also play an important role (Butot et al., 2009; da Silva et al., 2007).

Cooking procedures applied to shellfish in which an internal temperature reaches at least $90{ }^{\circ} \mathrm{C}$ for $1.5 \mathrm{~min}$ are considered adequate treatments to eliminate viral infectivity (Codex Alimentarius, 2012 ). Assuming that treatments at $95{ }^{\circ} \mathrm{C}$ for $15 \mathrm{~min}$ completely inactivate HuNoVs (Ettayebi et al., 2016), these results showed that the PMAxx-Triton pretreatment cannot completely prevent RT-qPCR amplification from thermally-inactivated HuNoVs in oysters, leading to an overestimation of potential infectious HuNoV. Nevertheless, the incorporation of the PMAxx pretreatment improves the discrimination between intact and altered HuNoV capsids.

\subsection{Application of the PMAxx-Triton pretreatment in naturally contaminated samples}

In order to evaluate the performance of the PMAxx-Triton pretreatment in naturally contaminated samples, sewage samples and oysters were analyzed with and without the 
PMAxx-Triton pretreatment. In parallel, naturally contaminated samples were heated at $99{ }^{\circ} \mathrm{C}$ for $5 \mathrm{~min}$ to assess the performance of the PMAxx-Triton pretreatment individually. Mengovirus recovery ranged from 4.37-13.3\%, and thus the results were considered valid (Comite Europeen de Normalisation, 2017). For sewage, the PMAxx-Triton pretreatment did not modify the levels of $\mathrm{HuNoV}$ quantification, indicating that most likely HuNoV genomes quantified in sewage corresponded to undamaged viruses (Table 4). As a control, the PMAxxTriton pretreatment completely removed the RT-qPCR signal of heat-treated sewage samples naturally contaminated with $\mathrm{HuNoV}$ (Table 4).

Currently, a pretreatment using intercalating dyes has only been applied in environmental waters for assessing enteric virus infectivity (Blanco, Guix, Fuster, Fuentes, Bartolomé, et al., 2017; Fuster et al., 2016; Leifels et al., 2016; Prevost et al., 2016; Randazzo et al., 2016a; Randazzo et al., 2017). For the first time, this study evaluated the potential of PMAxx-Triton pretreatment to discriminate between intact and altered $\mathrm{HuNoV}$ particles in naturally contaminated shellfish samples. Quantification of HuNoV GI and GII was performed in naturally contaminated oysters with and without the PMAxx-Triton pretreatment in parallel. Mengovirus recovery in oysters was calculated as $>1 \%$ for all the samples and then, the results were considered valid (Comite Europeen de Normalisation, 2017). As shown in Table 5, no significant differences were reported after the PMAxx-Triton pretreatment in oysters. Since the ISO procedure includes a proteinase $\mathrm{K}$ treatment to release viruses from shellfish tissues, the impact of this broadly reactive protease on norovirus capsid cannot be excluded. In order to confirm that the PMAxx-Triton pretreatment was able to reduce the signal of inactivated viruses in oyster concentrates, aliquot samples were heated for $5 \mathrm{~min}$ at $99{ }^{\circ} \mathrm{C}$ and quantified in parallel with and without the PMAxx-Triton pretreatment. As expected, heat treatment resulted in a reduction of HuNoV titers in all samples (Table 5), although in some of them the PMAxxTriton-RT-qPCR signal was not completely removed, indicating the need for including this control for complex matrices. Moreover, as reported for bioaccumulated oysters, heat treatment reduced the detection of HuNoVs by RT-qPCR. 
Despite the fact that the PMAxx-Triton pretreatment is a step forward to better interpret quantification of HuNoVs, this pretreatment still faces some challenges that need to be addressed. One of them is the fact that the PMAxx-Triton pretreatment has only been evaluated after thermal treatments. Viruses in water and food products may be exposed to different inactivation mechanisms, such us UV light, high pressure or the presence of antiviral compounds. Therefore, this pretreatment must be evaluated for each inactivation process separately. For instance, it was recently shown that inactivation of HuNoV GI and GII with epigallocatechin gallate, a natural compound, was not discriminated by the PMAxx-Triton pretreatment (Falco et al., 2017).

In conclusion, without having a robust method of cell-culture for assessing norovirus infectivity in water and food, RT-qPCR procedures are still the gold standard for HuNoV detection. Our results suggest that a PMAxx-Triton-RT-qPCR assay may still underestimate HuNoV inactivation by heat treatments in shellfish, specifically in oysters. However, adopting a PMAxx-Triton-RT-qPCR procedure in routine monitoring will allow for more accurate quantification of potentially infectious HuNoVs in water and shellfish samples, constituting a useful tool for future risk assessment studies.

\section{Acknowledgements}

This work was supported by the Spanish Ministry of Economy and Competitiveness (MINECO) (RYC-2012-09950 and RYC-2013-12442) and the Spanish National Institute for Agriculture and Food Research and Technology (INIA) co-financed by the European Social Fund (Project RTA2014-00024-C03). Financial support has been co-sponsored by the European Regional

Development Fund (FEDER). GS and JRD were supported by the "Ramón y Cajal" Young Investigator. The authors acknowledge to the Entidad de Saneamiento de Aguas Residuales (EPSAR) and to Global Omnium S.L. for the access to sewage and helping in sampling at EDAR Quart Benager. 
Table 1. Quantification of thermally-inactivated ( $99^{\circ} \mathrm{C}$ for $5 \mathrm{~min}$ ) HuNoV GI and GII suspensions inoculated in shellfish concentrates after PMAxx-Triton pretreatment and RT-qPCR

\section{Levels of $\mathrm{NoV}$ in shellfish concentrates ${ }^{\mathrm{a}}$ $(\log$ RT-PCRU/100 $\mu \mathrm{l})$}

\begin{tabular}{|c|c|c|c|c|c|c|}
\hline & & $\begin{array}{c}\text { PMAxx } \\
+ \\
\text { Triton } \\
\end{array}$ & High $^{b}$ & $\mathbf{R}^{\mathbf{c}}$ & Low & $\mathbf{R}$ \\
\hline \multirow[t]{4}{*}{ Mussels } & HuNoV GI & - & $4.75 \pm 0.20 \mathrm{~A}$ & & $3.39 \pm 0.07 \mathrm{~A}$ & \\
\hline & & + & $3.37 \pm 0.06 \mathrm{~B}$ & 1.38 & $2.31 \pm 0.06 \mathrm{~B}$ & 1.08 \\
\hline & HuNoV GII & - & $3.51 \pm 0.22 \mathrm{~A}$ & & $3.08 \pm 0.09 \mathrm{~A}$ & \\
\hline & & + & ND & $>3.51$ & ND & $>3.08$ \\
\hline \multirow[t]{4}{*}{ Oysters } & HuNoV GI & - & $4.11 \pm 0.13 \mathrm{~A}$ & & $3.17 \pm 0.23 \mathrm{~A}$ & \\
\hline & & + & $2.86 \pm 0.32 B$ & 1.25 & $2.73 \mathrm{~B} *$ & $>0.44$ \\
\hline & HuNoV GII & - & $2.82 \pm 0.08 \mathrm{~A}$ & & $1.86 \pm 0.16 \mathrm{~A}$ & \\
\hline & & + & $1.69 \pm 0.22 \mathrm{~B} * *$ & $>1.13$ & $\mathrm{ND}$ & $>1.86$ \\
\hline \multirow{4}{*}{$\begin{array}{l}\text { Common } \\
\text { cockles }\end{array}$} & HuNoV GI & - & $4.31 \pm 0.12 \mathrm{~A}$ & & $3.08 \pm 0.18 \mathrm{~A}$ & \\
\hline & & + & ND & $>4.31$ & ND & $>3.08$ \\
\hline & HuNoV GII & - & $2.96 \pm 0.09 \mathrm{~A}$ & & $2.17 \pm 0.12 \mathrm{~A}$ & \\
\hline & & + & $2.14 \pm 0.26 \mathrm{~B}$ & 0.82 & $1.76 \pm 0.18 \mathrm{~B}$ & 0.41 \\
\hline
\end{tabular}

${ }^{a}$ Results are mean values from four replicates, and HuNoV titers were obtained by RT-qPCR using a HuNoV standard curve based on RT-PCRU.

${ }^{b}$ Values with different letters in the same column and same matrix denote significant differences between treatments $(\mathrm{P}<0.05)$.

${ }^{c}$ Reduction in titers between thermally inactivated viruses before and after pretreatment.

*, one positive replicate out of four; **, two positive replicates out of four.

ND: Not detected 
Table 2. Performance of PMAxx-Triton pretreatment to discriminate between intact and thermally-inactivated $\mathrm{HuNoV}$ GI $\left(60,72\right.$ and $95^{\circ} \mathrm{C}$ for $\left.15 \mathrm{~min}\right)$ in PBS, sewage and bioaccumulated oysters

\begin{tabular}{|c|c|c|c|c|c|c|c|}
\hline \multirow{2}{*}{$\begin{array}{l}\text { HuNoV GI a,b } \\
(\log \text { RT-PCRU/100 } \\
\mu \mathrm{l})\end{array}$} & \multirow{2}{*}{$\begin{array}{c}\text { PMAxx } \\
+ \\
\text { Triton }\end{array}$} & \multicolumn{2}{|l|}{ PBS } & \multicolumn{2}{|l|}{ Sewage } & \multicolumn{2}{|c|}{$\begin{array}{l}\text { Bioaccumulated } \\
\text { oysters }\end{array}$} \\
\hline & & Mean \pm std & $\mathbf{R}$ & Mean \pm std & $\mathbf{R}$ & Mean \pm std & $\mathbf{R}$ \\
\hline \multirow[t]{2}{*}{ Intact } & - & $5.29 \pm 0.42 \mathrm{~A}$ & & $3.44 \pm 0.15 \mathrm{~A}$ & & $5.60 \pm 0.23 \mathrm{~A}$ & \\
\hline & + & $4.95 \pm$ & 0.34 & $3.09 \pm 0.22 \mathrm{~A}$ & 0.35 & $5.54 \pm 0.11 \mathrm{~A}$ & 0.06 \\
\hline \multirow[t]{2}{*}{ Treated at $60^{\circ} \mathrm{C}$} & & 5.27 & & 3.46 & & & \\
\hline & + & 2.43 & 2.84 & $3.22=$ & 0.24 & 4.86 & 0.16 \\
\hline \multirow[t]{2}{*}{ Treated at $72{ }^{\circ} \mathrm{C}$} & - & $5.42 \pm$ & & $3.40 \pm 0.12 \mathrm{~A}$ & & 4.84 & \\
\hline & + & $2.97 \pm 0.15 \mathrm{~B}$ & 2.45 & ND & $>3.40$ & $4.76 \pm 0.16 \mathrm{~A}$ & 0.08 \\
\hline \multirow[t]{2}{*}{ Treated at $95^{\circ} \mathrm{C}$} & - & $5.71 \pm 0.35 \mathrm{~A}$ & & $3.21 \pm 0.23 \mathrm{~A}$ & & $4.84 \pm 0.11 \mathrm{~A}$ & \\
\hline & + & $3.22 \pm 0.49 \mathrm{~B}$ & 2.49 & ND & $>3.21$ & $3.99 \pm 0.18 \mathrm{~A}$ & 0.85 \\
\hline
\end{tabular}

$\mathrm{R}$, reduction in titers obtained between samples before and after PMAxx-Triton pretreatment.

${ }^{a}$ Results are mean values from four replicates, and HuNoV titers were obtained by RT-qPCR using a HuNoV standard curve based on RT-PCRU.

${ }^{b}$ Values with different letters in the same column denote significant differences between treatments $(\mathrm{P}<0.05)$.

ND: Not detected 
Table 3. Performance of PMAxx pretreatment to discriminate between potentially intact and thermally-inactivated HuNoV GII $\left(60,72\right.$ and $95^{\circ} \mathrm{C}$ for $\left.15 \mathrm{~min}\right)$ in PBS, sewage and bioaccumulated oysters.

\begin{tabular}{|c|c|c|c|c|c|c|c|}
\hline \multirow{2}{*}{$\begin{array}{l}\text { HuNoV GII }{ }^{\text {a,b }} \\
(\log \text { RT-PCRU/100 } \\
\mu \mathrm{l})\end{array}$} & \multirow{2}{*}{$\begin{array}{c}\text { PMAxx } \\
+ \\
\text { Triton }\end{array}$} & PBS & \multicolumn{2}{|r|}{ Sewage } & \multirow[b]{2}{*}{$\mathbf{R}$} & \multicolumn{2}{|l|}{$\begin{array}{l}\text { Bioaccumulated } \\
\text { oysters }\end{array}$} \\
\hline & & Mean \pm std & $\mathbf{R}$ & Mean \pm std & & Mean \pm std & $\mathbf{R}$ \\
\hline \multirow[t]{2}{*}{ Intact } & - & $3.78 \pm 0.24 \mathrm{~A}$ & & $3.52 \pm 0.05 \mathrm{~A}$ & & $5.04 \pm 0.06 \mathrm{~A}$ & \\
\hline & + & $3.67 \pm 0.11 \mathrm{~A}$ & 0.11 & $3.42 \pm 0.11 \mathrm{~A}$ & 0.10 & $4.97 \pm 0.12 \mathrm{~A}$ & 0.07 \\
\hline \multirow[t]{2}{*}{ Treated at $60^{\circ} \mathrm{C}$} & - & $3.76 \pm 0.36 \mathrm{~A}$ & & $3.11 \pm 0.86 \mathrm{~A}$ & & $4.97 \pm 0.04 \mathrm{~A}$ & \\
\hline & + & $3.63 \pm 0.40 \mathrm{~A}$ & 0.13 & $3.10 \pm 0.18 \mathrm{~A}$ & 0.01 & $4.78 \pm 0.03 \mathrm{AB}$ & 0.19 \\
\hline \multirow[t]{2}{*}{ Treated at $72{ }^{\circ} \mathrm{C}$} & - & $3.11 \pm 0.81 \mathrm{~A}$ & & $3.40 \pm 0.14 \mathrm{~A}$ & & $4.53 \pm 0.06 \mathrm{~B}$ & \\
\hline & + & $1.41 \pm 0.63 \mathrm{C}$ & 1.70 & $2.61 \pm 0.15 B$ & 0.79 & $3.75 \pm 0.29 \mathrm{C} *$ & 0.78 \\
\hline \multirow[t]{2}{*}{ Treated at $95^{\circ} \mathrm{C}$} & - & $3.85 \pm 0.87 \mathrm{~A}$ & & $3.15 \pm 0.21 \mathrm{~A}$ & & $3.93 \pm 0.17 \mathrm{C}$ & \\
\hline & + & $2.29 \pm 0.35 \mathrm{~B}$ & 1.56 & ND & $>3.15$ & $2.86 \pm 0.04 \mathrm{D} *$ & 1.07 \\
\hline
\end{tabular}

*, two positive replicates out of four.

$\mathrm{R}$, reduction in titers obtained between samples before and after PMAxx-Triton pretreatment.

${ }^{a}$ Results are mean values from four replicates, and HuNoV titers were obtained by RT-qPCR using a HuNoV standard curve based on RT-PCRU.

${ }^{\mathrm{b}}$ Values with different letters in the same column denote significant differences between treatments $(\mathrm{P}<0.05)$.

ND: Not detected 
Table 4. Quantification of HuNoV GI and GII present in sewage by RT-qPCR and PMAxx-Triton RT-qPCR.

\begin{tabular}{|c|c|c|c|c|c|c|}
\hline \multirow[t]{2}{*}{ Sample } & \multirow[t]{2}{*}{ Treatment } & \multirow[t]{2}{*}{$\begin{array}{c}\text { PMAxx } \\
+ \\
\text { Triton }\end{array}$} & \multicolumn{2}{|c|}{$\begin{array}{l}\text { NoV GI }{ }^{\text {a,b }} \\
(\log \text { RT-PCRU/100 } \mu \mathrm{l})\end{array}$} & \multicolumn{2}{|c|}{$\begin{array}{l}\text { NoV GII }{ }^{\text {a,b }} \\
(\log \text { RT-PCRU/100 } \\
\mu \mathrm{l})\end{array}$} \\
\hline & & & Mean \pm SD & $\mathbf{R}$ & Mean \pm SD & $\mathbf{R}$ \\
\hline \multirow{4}{*}{ R4 } & untreated & - & ND & & $2.81 \pm 0.12 \mathrm{~A}$ & \\
\hline & & + & ND & & $1.22 \mathrm{~B} *$ & $>1.66$ \\
\hline & $5 \min$ a $99^{\circ} \mathrm{C}$ & - & ND & & $2.16 \pm 0.64 \mathrm{AB}$ & \\
\hline & & + & ND & & ND & $>2.16$ \\
\hline \multirow{4}{*}{$\mathrm{R} 8$} & untreated & - & $2.60 \mathrm{~A}$ & & $2.75 \pm 0.37 \mathrm{~A}$ & \\
\hline & & + & $<\mathrm{LOQ}$ & $>2.60$ & $2.36 \pm 0.09 \mathrm{~A}$ & 0.39 \\
\hline & $5 \min$ a $99^{\circ} \mathrm{C}$ & - & $<\mathrm{LOQ}$ & & $2.14 \mathrm{~A}$ & \\
\hline & & + & $<\mathrm{LOQ}$ & & ND & $>2.14$ \\
\hline \multirow{4}{*}{$\mathrm{R} 10$} & untreated & - & $2.41 \pm 0.29 \mathrm{~A}$ & & $2.75 \pm 0.02 \mathrm{~A}$ & \\
\hline & & + & ND & $>2.41$ & $1.59 \pm 0.29 B$ & 1.16 \\
\hline & 5 min a $99^{\circ} \mathrm{C}$ & - & $<\mathrm{LOQ}$ & & $2.93 \pm 0.03 \mathrm{~A}$ & \\
\hline & & + & ND & & ND & $>2.93$ \\
\hline \multirow{4}{*}{$\mathrm{R} 12$} & untreated & - & $3.44 \pm 0.15 \mathrm{~A}$ & & $3.52 \pm 0.05 \mathrm{~A}$ & \\
\hline & & + & $3.09 \pm 0.22 \mathrm{~A}$ & 0.35 & $3.42 \pm 0.11 \mathrm{AB}$ & 0.10 \\
\hline & $5 \min$ a $99^{\circ} \mathrm{C}$ & - & $3.21 \pm 0.23 \mathrm{~A}$ & & $3.15 \pm 0.21 \mathrm{~B}$ & \\
\hline & & + & ND & $>3.21$ & ND & $>3.15$ \\
\hline \multirow{4}{*}{ R19 } & untreated & - & $2.23 \pm 0.23 \mathrm{~A}$ & & $2.16 \pm 0.17 \mathrm{~A}$ & \\
\hline & & + & $2.27 \pm 0.35 \mathrm{~A}$ & 0.04 & $1.84 \pm 0.64 \mathrm{~A}$ & 0.32 \\
\hline & $5 \min$ a $99^{\circ} \mathrm{C}$ & - & ND & & $1.91 \pm 0.26 \mathrm{~A}$ & \\
\hline & & + & ND & & ND & $>1.91$ \\
\hline
\end{tabular}

$\mathrm{R}$, reduction in titers obtained between samples before and after PMAxx-Triton pretreatment.

*, one positive replicate out of four

ND: Not detected

LOQ, positive sample below the quantification limit

${ }^{a}$ Results are mean values from four replicates, and HuNoV titers were obtained by RT-qPCR using a HuNoV standard curve based on RT-PCRU.

${ }^{b}$ Values with different letters in the same column and same sample denote significant differences between treatments $(\mathrm{P}<0.05)$. 
Table 5. Quantification of HuNoV GI and GII present in naturally contaminated oysters by RT-qPCR and PMAxx-Triton RT-qPCR.

\begin{tabular}{|c|c|c|c|c|c|c|}
\hline \multirow[t]{2}{*}{ Sample } & \multirow[t]{2}{*}{ Treatment } & \multirow{2}{*}{$\begin{array}{c}\text { PMAxx } \\
+ \\
\text { Triton }\end{array}$} & \multicolumn{2}{|c|}{$\begin{array}{l}\text { NoV GI a,b } \\
(\log \text { RT-PCRU/100 } \mu \mathrm{l})\end{array}$} & \multicolumn{2}{|c|}{$\begin{array}{l}\text { NoV GII }{ }^{\mathrm{a}, \mathrm{b}} \\
(\log \text { RT-PCRU/100 } \mu \mathrm{l})\end{array}$} \\
\hline & & & Mean \pm SD & $\mathbf{R}$ & Mean \pm SD & $\mathbf{R}$ \\
\hline \multirow{4}{*}{$13 / 11$} & untreated & - & $3.43 \pm 0.21 \mathrm{~A}$ & \multirow{3}{*}{0} & $2.77 \pm 0.06 \mathrm{~A}$ & \multirow{3}{*}{0.10} \\
\hline & \multirow{3}{*}{5 min a $99^{\circ} \mathrm{C}$} & + & $3.48 \pm 0.18 \mathrm{~A}$ & & $2.67 \pm 0.16 \mathrm{~A}$ & \\
\hline & & - & $2.99 \pm 0.26 \mathrm{~A}$ & & $1.93 \pm 0.19 B$ & \\
\hline & & + & ND & $>2.99$ & ND & $>1.93$ \\
\hline \multirow{4}{*}{$13 / 018$} & untreated & - & $3.46 \pm 0.08 \mathrm{~A}$ & \multirow{3}{*}{0.36} & $1.61 \pm 0.23 \mathrm{~A}$ & \multirow{4}{*}{0.02} \\
\hline & \multirow{3}{*}{5 min a $99^{\circ} \mathrm{C}$} & + & $3.10 \pm 0.10 \mathrm{~A}$ & & $1.58 \pm 0.20 \mathrm{~A}$ & \\
\hline & & - & $3.07 \pm 0.30 \mathrm{~A}$ & & $1.40 \mathrm{~A} *$ & \\
\hline & & + & $2.02 \mathrm{~B} *$ & 1.05 & ND & \\
\hline \multirow{4}{*}{$14 / 22$} & untreated & - & $2.88 \pm 0.34 \mathrm{~A}$ & \multirow{3}{*}{$>0.33$} & $2.03 \pm 0.13 \mathrm{~A}$ & \multirow{3}{*}{0.11} \\
\hline & \multirow{3}{*}{5 min a $99^{\circ} \mathrm{C}$} & + & $2.55 \mathrm{~A} *$ & & $1.91 \pm 0.12 \mathrm{~A}$ & \\
\hline & & - & $2.02 \mathrm{~A} *$ & & $1.35 \pm 0.30 \mathrm{~B}$ & \\
\hline & & + & ND & $>2.02$ & ND & $>1.35$ \\
\hline \multirow{4}{*}{$14 / 24$} & untreated & - & $2.58 \pm 0.51 \mathrm{~A}$ & \multirow{3}{*}{0} & $2.42 \pm 0.58 \mathrm{~A}$ & \multirow{4}{*}{0.19} \\
\hline & \multirow{3}{*}{5 min a $99^{\circ} \mathrm{C}$} & + & $2.97 \pm 0.09 \mathrm{~A}$ & & $2.23 \pm 0.51 \mathrm{~A}$ & \\
\hline & & - & $2.33 \pm 0.44 \mathrm{~A}$ & & $1.66 \pm 0.29 \mathrm{~A}$ & \\
\hline & & + & $\mathrm{ND}$ & $>2.33$ & $1.42 \pm 0.02 \mathrm{~A} * *$ & \\
\hline \multirow{4}{*}{$13 / 030$} & untreated & - & $2.67 \pm 0.05 \mathrm{~A}$ & \multirow{4}{*}{0.10} & $1.85 \pm 0.10 \mathrm{~A}$ & \multirow{4}{*}{0.72} \\
\hline & & + & $2.57 \mathrm{~A} *$ & & $1.13 \mathrm{~B} *$ & \\
\hline & 5 min a $99^{\circ} \mathrm{C}$ & - & $2.38 \pm 0.10 \mathrm{~B}$ & & ND & \\
\hline & & + & $2.58 \mathrm{~A} *$ & & ND & \\
\hline
\end{tabular}

*, one positive replicate out of four; ${ }^{*}$, two positive replicates out of four.

$\mathrm{R}$, reduction in titers obtained between samples before and after viability pretreatment.

ND, Not Detected

${ }^{a}$ Results are mean values from four replicates, and NoV titers were obtained by RT-qPCR using a NoV standard curve based on RT-PCRU.

${ }^{b}$ Values with different letters in the same column and same matrix denote significant differences between treatments $(\mathrm{P}<0.05)$. 


\section{References}

Batz, M.B., Hoffmann, S.A., Morris, J.G., 2011. Ranking the risks: the 10 pathogen-food combinations with the greatest burden on public health. Emerging Pathogens Institute, University of Florida.

Blanco, A., Guix, S., Fuster, N., Fuentes, C., Bartolome, R., Cornejo, T., Pinto, R.M., Bosch, A., 2017. Norovirus in Bottled Water Associated with Gastroenteritis Outbreak, Spain, 2016. Emerging infectious diseases 23, 1531-1534.

Blanco, A., Guix, S., Fuster, N., Fuentes, C., Bartolomé, R., Cornejo, T., Pintó, R.M., Bosch, A., 2017. Norovirus in Bottled Water Associated with Gastroenteritis Outbreak, Spain, 2016. Emerging Infectious Diseases 23, 1531-1534.

Butot, S., Putallaz, T., Amoroso, R., Sanchez, G., 2009. Inactivation of Enteric Viruses in Minimally Processed Berries and Herbs. Applied and Environmental Microbiology 75, 41554161.

Butot, S., Putallaz, T., Sánchez, G., 2008. Effects of sanitation, freezing and frozen storage on enteric viruses in berries and herbs. International Journal of Food Microbiology 126, 30-35.

Campos, C.J.A., Lees, D.N., 2014. Environmental Transmission of Human Noroviruses in Shellfish Waters. Applied and Environmental Microbiology 80, 3552-3561.

Codex Alimentarius, 2012 Guidelines on the application of general principles of food hygiene to the control of viruses in food (p. 13). . Codex Committee on Food Hygiene,

Comite Europeen de Normalisation, I., 2017. Microbiology of the food chain - Horizontal method for determination of hepatitis A virus and norovirus using real-time RT-PCR - Part 1:

Method for quantification (ISO 15216-1:2017), European Standard, pp. 3pp.-3pp.

da Silva, A.K., Le Saux, J.C., Parnaudeau, S., Pommepuy, M., Elimelech, M., Le Guyader, F.S., 2007. Evaluation of removal of noroviruses during wastewater treatment, using real-time reverse transcription-PCR: different behaviors of genogroups I and II. Appl Environ Microbiol 73, 7891-7897.

Dancho, B.A., Chen, H., Kingsley, D.H., 2012. Discrimination between infectious and noninfectious human norovirus using porcine gastric mucin. International Journal of Food Microbiology 155, 222-226.

Drouaz, N., Schaeffer, J., Farkas, T., Le Pendu, J., Le Guyader, F.S., 2015. Tulane Virus as a Potential Surrogate To Mimic Norovirus Behavior in Oysters. Applied and Environmental Microbiology 81, 5249-5256.

EFSA and ECDC, 2016. The European Union summary report on trends and sources of zoonoses, zoonotic agents and food-borne outbreaks in 2015. EFSA Journal 14.

Elizaquivel, P., Aznar, R., Sanchez, G., 2014. Recent developments in the use of viability dyes and quantitative PCR in the food microbiology field. Journal of Applied Microbiology $116,1-13$.

Escudero-Abarca, B.I., Rawsthorne, H., Goulter, R.M., Suh, S.H., Jaykus, L.A., 2014. Molecular methods used to estimate thermal inactivation of a prototype human norovirus: more heat resistant than previously believed? Food microbiology 41, 91-95.

Ettayebi, K., Crawford, S.E., Murakami, K., Broughman, J.R., Karandikar, U., Tenge, V.R., Neill, F.H., Blutt, S.E., Zeng, X.-L., Qu, L., Kou, B., Opekun, A.R., Burrin, D., Graham, D.Y., Ramani, S., Atmar, R.L., Estes, M.K., 2016. Replication of human noroviruses in stem cellderived human enteroids. Science 353, 1387-1393.

European Food Safety, A., 2016. Technical specifications for a European baseline survey of norovirus in oysters. EFSA Journal 14, 4414-n/a.

Falco, I., Randazzo, W., Gomez-Mascaraque, L., Aznar, R., Lopez-Rubio, A., Sanchez, G., 2017. Effect of (-)-epigallocatechin gallate at different $\mathrm{pH}$ conditions on enteric viruses. LWT -Food Science and Technology 81, 250-257.

Fuster, N., Pinto, R.M., Fuentes, C., Beguiristain, N., Bosch, A., Guix, S., 2016. Propidium monoazide RTqPCR assays for the assessment of hepatitis A inactivation and for a better estimation of the health risk of contaminated waters. Water Research 101, 226-232. 
Hall, A.J., Wikswo, M.E., Pringle, K., Gould, L.H., Parashar, U.D., 2014. Vital Signs: Foodborne Norovirus Outbreaks - United States, 2009-2012. Morb. Mortal. Weekly Rep. 63, 491-495.

Hassard, F., Sharp, J.H., Taft, H., LeVay, L., Harris, J.P., McDonald, J.E., Tuson, K., Wilson, J., Jones, D.L., Malham, S.K., 2017. Critical Review on the Public Health Impact of Norovirus Contamination in Shellfish and the Environment: A UK Perspective. Food and environmental virology 9, 123-141.

Hewitt, J., Greening, G.E., 2004. Survival and Persistence of Norovirus, Hepatitis A Virus, and Feline Calicivirus in Marinated Mussels. Journal of Food Protection 67, 1743-1750.

Hewitt, J., Greening, G.E., 2006. Effect of heat treatment on hepatitis a virus and norovirus in New Zealand Greenshell mussels (Perna canaliculus) by quantitative real-time reverse transcription PCR and cell culture. Journal of Food Protection 69, 2217-2223.

Iritani, N., Kaida, A., Abe, N., Kubo, H., Sekiguchi, J.-I., Yamamoto, S.P., Goto, K., Tanaka, T., Noda, M., 2014. Detection and Genetic Characterization of Human Enteric Viruses in Oyster-Associated Gastroenteritis Outbreaks Between 2001 and 2012 in Osaka City, Japan. Journal of Medical Virology 86, 2019-2025.

Jeong, M.I., Park, S.Y., Ha, S.D., 2017. Thermal inactivation of human norovirus on spinach using propidium or ethidium monoazide combined with real-time quantitative reverse transcription-polymerase chain reaction. Food Control 78, 79-84.

Lamhoujeb, S., Fliss, I., Ngazoa, S.E., Jean, J., 2008. Evaluation of the persistence of infectious human noroviruses on food surfaces by using real-time nucleic acid sequence-based amplification. Applied and Environmental Microbiology 74, 3349-3355.

Le Guyader, F.S., Atmar, R.L., Le Pendu, J., 2012. Transmission of viruses through shellfish: when specific ligands come into play. Current Opinion in Virology 2, 103-110.

Le Mennec, C., Parnaudeau, S., Rumebe, M., Le Saux, J.-C., Piquet, J.-C., Le Guyader, S.F., 2017. Follow-Up of Norovirus Contamination in an Oyster Production Area Linked to Repeated Outbreaks. Food and Environmental Virology 9, 54-61.

Leifels, M., Jurzik, L., Wilhelm, M., Hamza, I.A., 2015. Use of ethidium monoazide and propidium monoazide to determine viral infectivity upon inactivation by heat, UV- exposure and chlorine. Int. J. Hyg. Environ. Health 218, 686-693.

Leifels, M., Jurzik, L., Wilhelm, M., Hamza, I.A., 2016. Corrigendum to: "Use of ethidium monoazide and propidium monoazide to determine viral infectivity upon inactivation by heat, UV-exposure and chlorine" [Int. J. Hyg. Environ. Health 218 (8) (2015) 686-693]. Int. J. Hyg. Environ. Health 219, 232-232.

Li, X., Huang, R., Chen, H., 2017. Evaluation of Assays to Quantify Infectious Human Norovirus for Heat and High-Pressure Inactivation Studies Using Tulane Virus. Food and Environmental Virology, 1-12.

Lunestad, B.T., Maage, A., Roiha, I.S., Myrmel, M., Svanevik, C.S., Duinker, A., 2016. An Outbreak of Norovirus Infection from Shellfish Soup Due to Unforeseen Insufficient Heating During Preparation. Food and Environmental Virology 8, 231-234.

McLeod, C., Polo, D., Le Saux, J.-C., Le Guyader, F.S., 2017. Depuration and Relaying: A Review on Potential Removal of Norovirus from Oysters. Comprehensive Reviews in Food Science and Food Safety 16, 692-706.

Moreno, L., Aznar, R., Sanchez, G., 2015. Application of viability PCR to discriminate the infectivity of hepatitis A virus in food samples. International Journal of Food Microbiology 201, $1-6$.

Nowak, P., Topping, J.R., Fotheringham, V., Gallimore, C.I., Gray, J.J., Iturriza-Gomara, M., Knight, A.I., 2011. Measurement of the virolysis of human GII.4 norovirus in response to disinfectants and sanitisers. Journal of Virological Methods 174, 7-11.

Parshionikar, S., Laseke, I., Fout, G.S., 2010. Use of Propidium Monoazide in Reverse Transcriptase PCR To Distinguish between Infectious and Noninfectious Enteric Viruses in Water Samples. Applied and Environmental Microbiology 76, 4318-4326.

Pinto, R.M., Diez, J.M., Bosch, A., 1994. Use of the colonic-carcinoma cell-line Caco-2 for in-vivo amplification and detection of enteric viruses. Journal of Medical Virology 44, 310-315. 
Prevost, B., Goulet, M., Lucas, F.S., Joyeux, M., Moulin, L., Wurtzer, S., 2016. Viral persistence in surface and drinking water: Suitability of PCR pre-treatment with intercalating dyes. Water Research 91, 68-76.

Randazzo, W., Lopez-Galvez, F., Allende, A., Aznar, R., Sanchez, G., 2016a. Evaluation of viability PCR performance for assessing norovirus infectivity in fresh-cut vegetables and irrigation water. International Journal of Food Microbiology 229, 1-6.

Randazzo, W., Lopez-Galvez, F., Allende, A., Aznar, R., Sanchez, G., 2016b. Evaluation of viability PCR performance for assessing norovirus infectivity in fresh-cut vegetables and irrigation water. Int J Food Microbiol 229, 1-6.

Randazzo, W., Piqueras, J., Rodríguez-Díaz, J., Aznar, R., Sánchez, G., 2017. Improving efficiency of viability-qPCR for selective detection of infectious HAV in food and water samples. Journal of Applied Microbiology.

Sanchez, G., Aznar, R., Martinez, A., Rodrigo, D., 2011. Inactivation of Human and Murine Norovirus by High-Pressure Processing. Foodborne Pathogens and Disease 8, 249-253.

Tan, M., Jiang, X., 2005. Norovirus and its histo-blood group antigen receptors: an answer to a historical puzzle. Trends in Microbiology 13, 285-293.

Tang, Q., Li, D., Xu, J., Wang, J., Zhao, Y., Li, Z., Xue, C., 2010. Mechanism of inactivation of murine norovirus-1 by high pressure processing. International Journal of Food Microbiology 137, 186-189.

WHO, 2015. WHO estimates of the global burden of foodborne diseases. Foodborne diseases burden epidemiology reference group 2007-2015. World Health Organization, p. 255. 